\title{
Contrast agent volume in coronary computer tomography angiography - where are the limits?
}

\author{
Grigorios Korosoglou $^{1,2}$, Sorin Giusca ${ }^{1,2}$ \\ ${ }^{1}$ GRN Hospital Weinheim, Cardiology, Vascular Medicine \& Pneumology, Weinheim, Germany; ${ }^{2}$ Cardiac Imaging Center Weinheim, Hector \\ Foundation, Weinheim, Germany
}

Correspondence to: Prof. Dr. Grigorios Korosoglou. GRN Hospital Weinheim, Department of Cardiology \& Vascular Medicine, Roentgenstrasse 1, D-69469, Weinheim, Germany. Email: gkorosoglou@hotmail.com.

Comment on: Jin L, Jie B, Gao Y, et al. Low dose contrast media in step-and-shoot coronary angiography with third-generation dual-source computed tomography: feasibility of using $30 \mathrm{~mL}$ of contrast media in patients with body surface area $<1.7 \mathrm{~m}^{2}$. Quant Imaging Med Surg 2021;11:2598-609.

Submitted May 07, 2021. Accepted for publication May 14, 2021.

doi: 10.21037/qims-21-488

View this article at: http://dx.doi.org/10.21037/qims-21-488

Coronary artery disease (CAD) is still a major public health problem, remaining the most common cause of death and disability globally and being associated with relevant costs for our health care system $(1,2)$. It can present in chronic or stable forms, currently named chronic coronary syndromes but also in acute forms ranging from unstable angina to myocardial infarction with cardiogenic shock or sudden cardiac death. The work-up of patients with known or suspected CAD is complex and usually involves a stepwise approach that includes clinical and demographic data, non-invasive tests and if required invasive coronary angiography (3). Recent data have revealed a lower pre-test probability in patients with CAD than previously anticipated (4). In parallel, a paradigm shift occurred in the evaluation of patients with suspected $\mathrm{CAD}$, with the focus moving to non-invasive imaging techniques. Currently, the clinician can choose between imaging tests that aim at identifying myocardial ischemia such as stress-echocardiography, stress cardiac magnetic resonance imaging or myocardial scintigraphy and direct non-invasive anatomical imaging of the coronary tree using coronary computer tomography angiography (CCTA) (5). In the last decades, an abundance of studies was published, which cemented the central role of CCTA in the diagnostic approach of patients with known and suspected CAD. In this regard, CCTA was shown to provide (I) excellent negative predictive value and very good specificity for identifying relevant CAD, (II) in depth evaluation of the various stages and severity of the coronary atherosclerotic process, (III) functional information related to the hemodynamic significance of the coronary stenosis using $\mathrm{FFR}_{\mathrm{CT}}$ and, most importantly, (IV) definite improvement of clinical outcomes (6).

Clinicians need however, to be aware of two relevant risks associated with a CCTA examination, which are (I) radiation exposure and (II) complications related to the administration of iodine contrast agent. Regarding radiation exposure, technological advancements within the last decades allowed for a significant reduction of the radiation exposure for the patients. Thus, the radiation exposure normally seen with spiral acquisitions $(9-22 \mathrm{mSv})$ can be significantly reduced using prospective step and shoot protocols $(2-4 \mathrm{mSv})$ and further minimized to $<1 \mathrm{mSv}$ by employing high-pitch spiral protocols using modern dual source machines in selected patients (7-9). Studies have proven the diagnostic feasibility of the high-pitch spiral technology and, although this type of acquisition cannot be applied in all scenarios, it already entered the clinical routine (10). The exceptionally low radiation exposure opens the door for performing longitudinal CCTA studies and thus for providing important information related to the evolution of the atherosclerotic process and its response to specific lipid-lowering or anti-inflammatory therapies.

The administration of contrast agent, on the other hand, is related to possible allergic reactions, hyperthyroidism 
and worsening of the renal function. Especially in the case of contrast induced nephropathy, a dose-dependent relationship between the volume of contrast agent administrated and the risk of worsening of the renal function is widely accepted. However, according to recent reports, the risk for kidney injury due to contrast agent injections might have been overstated in the past $(11,12)$. It would therefore by desirable to use the lowest volume of contrast agent possible without sacrificing the image quality. Most of the current CCTA scan protocols employ between 60 and $80 \mathrm{~mL}$ of iodinated contrast. The volume of contrast used is dependent on numerous factors such as the patient's habitus, method for determining the appropriate time frame for the acquisition (i.e., bolus tracking or test bolus), speed of administration of the contrast agent and type of CCTA protocol (13). Previous studies have reported good results with volumes as low as $40 \mathrm{~mL}$ of contrast agent (14). In the current study, Jin et al. tested an even lower dose of contrast agent (15). Thus, they evaluated 53 patients who underwent CCTA using $30 \mathrm{~mL}$ contrast agent [iobitridol, $350 \mathrm{mg}$ iodine $(\mathrm{mgI}) / \mathrm{mL}$ ] and compared the data regarding diagnostic image quality with a group of 50 patients who underwent a CCTA using a routine dose contrast agent $(0.7 \mathrm{~mL} / \mathrm{Kg}, \approx 42 \mathrm{~mL})$. In all patients step and shoot protocols were employed, and the optimal time of acquisition was determined using the bolus tracking method. As expected, the authors found lower opacification in the coronary arteries in terms of $\mathrm{HU}$ in the low dose contrast agent group. However, the diagnostic image quality was deemed similar between the two groups. The results are promising and especially noteworthy as the authors used a step and shoot protocol. Thus, it appears that a low volume of contrast agent can be used in patients with higher heart rates, where high pitch spiral protocols would not be feasible. However, the data must be interpreted with care. As the authors stated, the population studied had a low body mass index (BMI), which may not be representative of the general CAD population. Patients with higher BMI usually need higher volumes of contrast agent in comparison to standard protocols (16). Secondly, there was no reference for assessing the severity of the CAD. Although the readers agreed that the diagnostic image quality was good in both groups, it is difficult to infer that the evaluation of the severity of the coronary stenosis was accurate in both groups without having follow-up data or an invasive reference standard. Lastly, the authors do not provide any information related to the calcium burden of the coronary arteries. The accuracy of CCTA is diminished in patients with high calcium burden and based on the data provided it is difficult to assess the feasibility of administrating a low dose contrast agent in patients with high calcium scores (17).

Overall, the study provides an important milestone to the body of literature related to CCTA and supports to use of low volumes of contrast agent in selected populations who undergo a CCTA examination, thus making CCTA even safer in the daily routine and importantly without sacrificing the diagnostic accuracy of the method, which is essential for both diagnostic classification and risk stratification of our patients.

\section{Acknowledgments}

Funding: None.

\section{Footnote}

Provenance and Peer Review: This article was commissioned by the editorial office, Quantitative Imaging in Medicine and Surgery. The article did not undergo external peer review.

Conflicts of Interest: Both authors have completed the ICMJE uniform disclosure form (available at http://dx.doi. org/10.21037/qims-21-488). The authors have no conflicts of interest to declare.

Ethical Statement: The authors are accountable for all aspects of the work in ensuring that questions related to the accuracy or integrity of any part of the work are appropriately investigated and resolved.

Open Access Statement: This is an Open Access article distributed in accordance with the Creative Commons Attribution-NonCommercial-NoDerivs 4.0 International License (CC BY-NC-ND 4.0), which permits the noncommercial replication and distribution of the article with the strict proviso that no changes or edits are made and the original work is properly cited (including links to both the formal publication through the relevant DOI and the license). See: https://creativecommons.org/licenses/by-nc-nd/4.0/.

\section{References}

1. Benjamin EJ, Virani SS, Callaway CW, Chamberlain AM, Chang AR, Cheng S, et al. Heart Disease and Stroke Statistics-2018 Update: A Report From the American Heart Association. Circulation 2018;137:e67-e492. 
2. GBD 2017 DALYs and HALE Collaborators. Global, regional, and national disability-adjusted life-years (DALYs) for 359 diseases and injuries and healthy life expectancy (HALE) for 195 countries and territories, 1990-2017: a systematic analysis for the Global Burden of Disease Study 2017. Lancet 2018;392:1859-922.

3. Knuuti J, Wijns W, Saraste A, Capodanno D, Barbato E, Funck-Brentano C, et al. 2019 ESC Guidelines for the diagnosis and management of chronic coronary syndromes. Eur Heart J 2020;41:407-77.

4. Juarez-Orozco LE, Saraste A, Capodanno D, Prescott E, Ballo H, Bax JJ, Wijns W, Knuuti J. Impact of a decreasing pre-test probability on the performance of diagnostic tests for coronary artery disease. Eur Heart J Cardiovasc Imaging 2019;20:1198-207.

5. Korosoglou G, Giusca S, Gitsioudis G, Erbel C, Katus HA. Cardiac magnetic resonance and computed tomography angiography for clinical imaging of stable coronary artery disease. Diagnostic classification and risk stratification. Front Physiol 2014;5:291.

6. Abdelrahman KM, Chen MY, Dey AK, Virmani R, Finn AV, Khamis RY, Choi AD, Min JK, Williams MC, Buckler AJ, Taylor CA, Rogers C, Samady H, Antoniades C, Shaw LJ, Budoff MJ, Hoffmann U, Blankstein R, Narula J, Mehta NN. Coronary Computed Tomography Angiography From Clinical Uses to Emerging Technologies: JACC State-of-the-Art Review. J Am Coll Cardiol 2020;76:1226-43.

7. Earls JP, Berman EL, Urban BA, Curry CA, Lane JL, Jennings RS, McCulloch CC, Hsieh J, Londt JH. Prospectively gated transverse coronary CT angiography versus retrospectively gated helical technique: improved image quality and reduced radiation dose. Radiology 2008;246:742-53.

8. DeFrance T, Dubois E, Gebow D, Ramirez A, Wolf F, Feuchtner GM. Helical prospective ECG-gating in cardiac computed tomography: radiation dose and image quality. Int J Cardiovasc Imaging 2010;26:99-107.

9. Hausleiter J, Bischoff B, Hein F, Meyer T, Hadamitzky M, Thierfelder C, Allmendinger T, Flohr TG, Schömig A, Martinoff S. Feasibility of dual-source cardiac CT angiography with high-pitch scan protocols. J Cardiovasc Comput Tomogr 2009;3:236-42.

10. Achenbach S, Marwan M, Ropers D, Schepis T, Pflederer T, Anders K, Kuettner A, Daniel WG, Uder M, Lell MM. Coronary computed tomography angiography with a consistent dose below $1 \mathrm{mSv}$ using prospectively electrocardiogram-triggered high-pitch spiral acquisition. Eur Heart J 2010;31:340-6.

11. Laskey WK, Jenkins C, Selzer F, Marroquin OC, Wilensky RL, Glaser R, Cohen HA, Holmes DR Jr; NHLBI Dynamic Registry Investigators. Volume-to-creatinine clearance ratio: a pharmacokinetically based risk factor for prediction of early creatinine increase after percutaneous coronary intervention. J Am Coll Cardiol 2007;50:584-90.

12. Davenport MS, Perazella MA, Yee J, Dillman JR, Fine D, McDonald RJ, Rodby RA, Wang CL, Weinreb JC. Use of Intravenous Iodinated Contrast Media in Patients with Kidney Disease: Consensus Statements from the American College of Radiology and the National Kidney Foundation. Radiology 2020;294:660-8.

13. Bae KT. Intravenous contrast medium administration and scan timing at CT: considerations and approaches. Radiology 2010;256:32-61.

14. Benz DC, Gräni C, Hirt Moch B, Mikulicic F, Vontobel J, Fuchs TA, Stehli J, Clerc OF, Possner M, Pazhenkottil AP, Gaemperli O, Buechel RR, Kaufmann PA. Minimized Radiation and Contrast Agent Exposure for Coronary Computed Tomography Angiography: First Clinical Experience on a Latest Generation 256-slice Scanner. Acad Radiol 2016;23:1008-14.

15. Jin L, Jie B, Gao Y, Jiang A, Weng T, Li M. Low dose contrast media in step-and-shoot coronary angiography with third-generation dual-source computed tomography: feasibility of using $30 \mathrm{~mL}$ of contrast media in patients with body surface area $<1.7 \mathrm{~m} 2$. Quant Imaging Med Surg 2021;11:2598-609.

16. Mangold S, Wichmann JL, Schoepf UJ, Litwin SE, Canstein C, Varga-Szemes A, Muscogiuri G, Fuller SR, Stubenrauch AC, Nikolaou K, De Cecco CN. Coronary CT angiography in obese patients using 3(rd) generation dual-source CT: effect of body mass index on image quality. Eur Radiol 2016;26:2937-46.

17. Qi L, Tang LJ, Xu Y, Zhu XM, Zhang YD, Shi HB, Yu RB. The Diagnostic Performance of Coronary CT Angiography for the Assessment of Coronary Stenosis in Calcified Plaque. PLoS One 2016;11:e0154852.

Cite this article as: Korosoglou G, Giusca S. Contrast agent volume in coronary computer tomography angiography-where are the limits? Quant Imaging Med Surg 2021;11(10):45114513. doi: 10.21037/qims-21-488 